\title{
Trunk Muscle Activity Affects the Level of Performance in Human Body
}

\author{
Satoru Kai \\ Faculty of Allied Health Sciences, Kansai University of Welfare Sciences, \\ Japan
}

\section{Introduction}

\subsection{To attain an excellent body performance level}

In rehabilitation practices, we therapists often offer support to patients so they can perform the very basic operations smoothly, such as getting up, standing up and walking. A decrease in daily life activity after a fall-caused fracture among senior citizens has now become an object of public concern in rapidly graying societies. Various approaches to fall prevention have therefore been tried, particularly from the viewpoint of preventive medicine. We also lend support to precisely those seniors with decreased body performance so as to improve that very performance level. We shall clarify in what follows how excellent body performance levels can be attained by activating the trunk muscle activity.

\subsection{Why we focus on the deep muscle of the trunk}

Lower trunk, or abdominal-dorsal part of the spine supports the body, has the following support system. The back is supported by the spine, the front is protected by rectus abdominal muscle between the ribs and pubic bone, and the lateral abdomen on each side is covered by three muscles, i.e., the external oblique muscle, the internal oblique muscle, and the transversus abdominis muscle (Fig. 1). The pelvis serves as the trunk's lower border, while the upper part, or abdominal cavity, is demarcated by the diaphragm. Transversus abdominis muscle, a deep muscle, plays a role of a corset together with the lumbodorsal fascia of the back.

In more details, anterolateral abdominal muscles and the muscles that form the roof (diaphragm), floor (pelvic floor muscles) and posterolateral (quadratus lumborum and psoas) aspects of the abdominal cavity contribute the control of the lumbar spine and pelvis (Richardson et al., 2004). Transversus abdominis muscle, the deepest of the abdominal muscles, arises from the thoracolumbar fascia between the iliac crest and the twelfth rib at the lateral raphe, the internal aspects of the lower six costal cartilages, where it interdigitates with the diaphragm, the lateral third of the inguinal ligament and the anterior two-thirds of the inner lip of the iliac crest (Richardson et al., 2004). Internal oblique muscle forms the middle layer of the lateral abdominal wall, with a muscular attachment to the lateral twothirds of the inguinal ligament, the anterior two-thirds of the iliac crest and the lateral raphe of the thoracolumbar fascia in a band $2-3 \mathrm{~cm}$ wide, attaching to fibers of the deep lamina arising from the L3 spinous process (Richardson et al., 2004). External oblique muscle is the 
most superficial of the lateral abdominal muscles. It arises via eight digitations from the external surface of the lower eight ribs (Richardson et al., 2004).

The global muscles such as the obliques, rectus abdominis, erector spinae and superficial multifidi are designed for movement but not for stability (Lee, 2004). The trunk stability is important for trunk mobility. Stability is achieved through motion, not rigidity (Lee, 2004). The transversus abdominis muscle, or trunk stabilizer muscle, is controlled by voluntary contraction, because it is a skeletal muscle. It is therefore important to keep transversus abdominal muscle ready for action at any given time. Transversus abdominis muscle is also an anticipatory muscle for stabilization of the lower back and is recruited prior to the initiation of any movement of the upper or lower extremity (Lee, 2004).

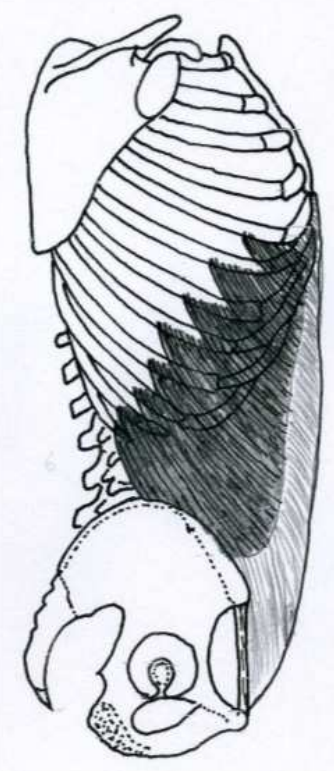

a.

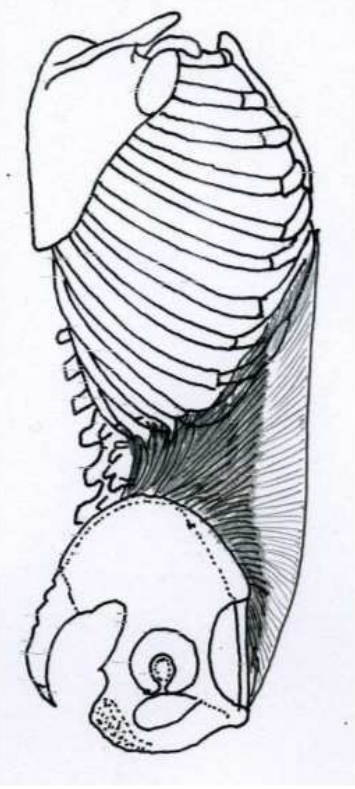

b.

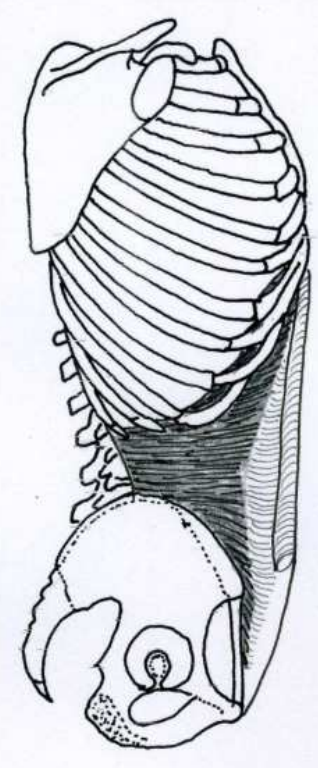

c.

Fig. 1. Lateral abdominal muscles.

a. External oblique muscle: superficial layer

b. Internal oblique muscle: middle layer

c. Transversus abdominis muscle: deep layer

\section{Health science research making use of electromyography}

We have continued to examine body performance levels in terms of electromyography (Kai et al., 2008a, 2008b). Electromyographic waves can shed light on various phenomena through frequency analysis and wavelet transform, among others. Surface electrodes have proved to be a useful non-invasive tool to measure body performance levels. A fair number of researchers have argued, however, that once electrodes are detached after a measurement, the very conditions that have given the readings are lost, reducing the reliability of the data considerably. That may well be one of the limits of the analysis of body 
functions by means of electromyographs. (We are dealing with living human bodies after all.) There is a method of regularizing the myogenic potential, however, if one takes into account the amount of muscle activity at the time of its maximum isometric contraction. One may still argue that there is a possibility that the amount of muscle activity at maximum isometric contraction may change through long-term intervention. Real changes in the performance level may not be caught by the \%MVC evaluation over time. To address this weakness in the research protocol directly, we have devised a system whereby the intervention effect is measured and evaluated on the same day.

\section{To improve standing balance}

\subsection{Trunk muscle activity while moving from two-leg to one-leg standing in healthy elderly adults (Kai et al., 2008b)}

Standing balance ability covers static and dynamic balancing. When a subject is moving, such as in walking, dynamic balancing is needed for him to fulfill the needed capacity of balance. We have singled out anticipatory postural adjustment for examination from among the various factors that figure in the balance ability. Anticipatory postural adjustment refers to an adjustment made in a subject's posture in which his weight gathers in the left, for instance, before he raises the right leg while standing. We have analyzed the muscle activity of the trunk and the hip joint while he shifts from two-leg to one-leg standing. Electromyographic activities were recorded of left internal oblique, left multifidus, left gluteus medius, and right iliopsoas muscles by surface-type electromyography (Fig. 2). No differences in muscle activity were found between young subjects and healthy elderly adults. We therefore concluded that healthy elderly adults in general have kept the muscle activity level necessary for anticipatory postural adjustments.

\section{Elderly person}

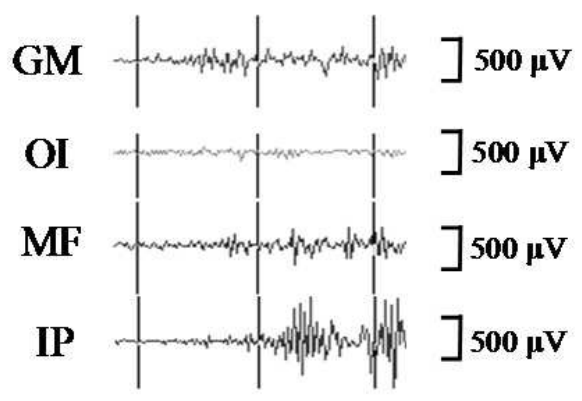

A
B

\section{Young person}

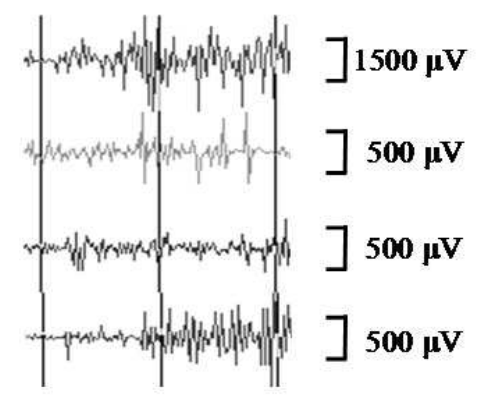

A

Abbreviations, GM, gluteus medius muscle; OI, internal oblique muscle (obliquus internus abdominis ); MF, multifidus muscle; IP, ilio-psoas muscle;

(Reproduced with permission from Kai et al., 2008b, p.78.)

Fig. 2. Representative EMG of GM, OI, MF and IP.

A: 500 ms before the start of raising the right foot.

$\mathrm{B}$ : just before the start of raising the right foot. 
3.2 Immediate effect of trunk muscle training in healthy elderly adult (Kai et al., 2008a) We are also doing research on fall prevention among the elderly. Specifically, we are examining how they can improve their body performance by activating trunk muscles for posture control. We have focused on just those elderly people with rather poor balance while standing and examined their postural adjustment before and after a training session in activating internal oblique muscle. We found that \% integrated electromyography and the coefficient of variation of internal oblique muscle decreased significantly, and \% integrated electromyography of multifidus muscle decreased under action. In gluteus medius muscle, on the other hand, no changes were observed before and after the training (Table 1). Based on these results, we suggest that the training method adopted here may prove useful in activating a series of smooth activities of lower trunk muscles during action.

\begin{tabular}{lllllll}
\hline Muscle & OI & \multicolumn{5}{c}{ MF } \\
\hline & \%iEMG & CV & \%iEMG & CV & \%iEMG & CV \\
\hline Pre-training & $19.08 \pm 2.43$ & $37.57 \pm 10.06$ & $5.14 \pm 1.04$ & $32.24 \pm 16.20$ & $6.99 \pm 1.41$ & $25.99 \pm 15.01$ \\
Post-training & $15.61 \pm 2.42^{*}$ & $19.38 \pm 10.16^{*}$ & $3.93 \pm 0.55^{*}$ & $21.41 \pm 12.73$ & $6.33 \pm 1.36$ & $26.18 \pm 11.13$ \\
\hline
\end{tabular}

${ }^{*} \mathrm{p}<0.01$ : pre-training vs post-training

Mean \pm standard deviation

Abbreviations, OI, internal oblique muscle (obliquus internus abdominis); MF, multifidus muscle;

$\mathrm{GM}$, gluteus medius muscle; $\mathrm{CV}$, coefficient of variation.

(Reproduced with permission from Kai et al., 2008a, p.64.)

Table 1. Average \%iEMG and coefficient of variation of 10 intervals before and after the training.

\subsection{Immediate effect of trunk muscle training in young healthy people}

We shall describe what effect trunk muscle training had among young healthy people in their ability of one-leg standing balance. Though they are no doubt needed, trunk muscles of the abdomen are not used very much in daily life. In healthy young women in Japan in particular, physical training is not part of their lifestyle to begin with. In the present study, we shall clarify how activation of trunk muscles can lead to alleviation of unsteadiness in their center of gravity during one-leg standing. Eighteen healthy adult women (average age 21.5 years old; range 20-23 years old) participated in the study. Unsteadiness of their center of gravity during one-leg standing was measured before and after a seat sitting balance exercise. While the subjects gazed forward while standing first on the right leg, the total tracks length was measured for 30 seconds; and then the same was repeated on the left leg. In the seat sitting balance exercise, the subjects gazed forward with both legs off of the floor and both arms hung loosely down, and they maintained the seat sitting for 2 minutes on a balance cushion (Fig.3). Results were that those women poor in balance with $100 \mathrm{~cm}$ or more in total tracks length before the exercise (Group A, and less than $100 \mathrm{~cm}$ in total tracks length is Group B) showed significant decreases in the total tracks length (Fig. 4). The finding suggests that trunk muscle training was effective in improving one-leg standing balance ability. We also suggest that activation of trunk muscles does influence balance taking while standing. 


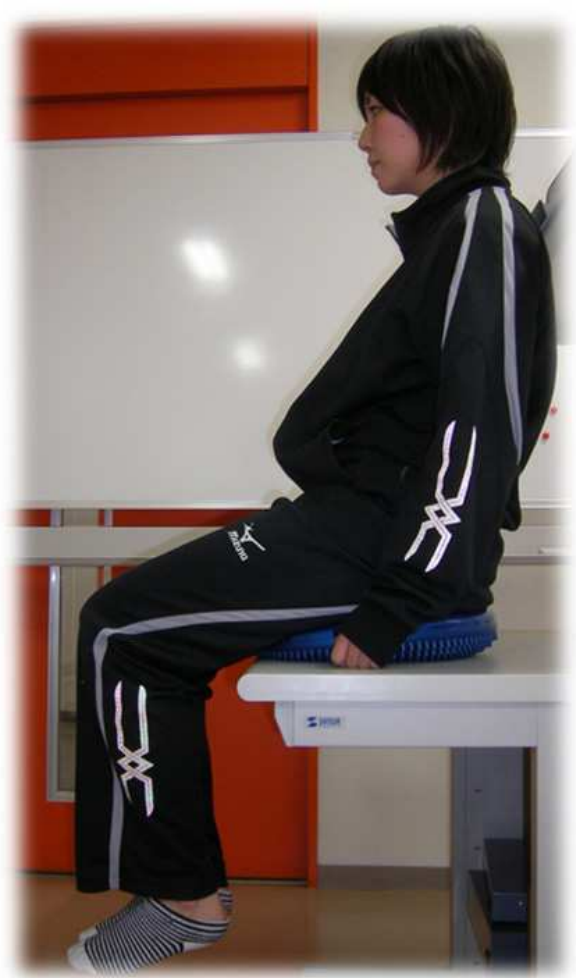

Fig. 3. The seat sitting balance exercise.

\section{Group A*}

\section{Right Side}

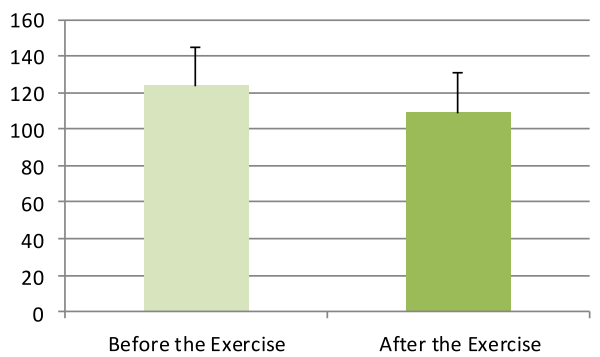

Left Side

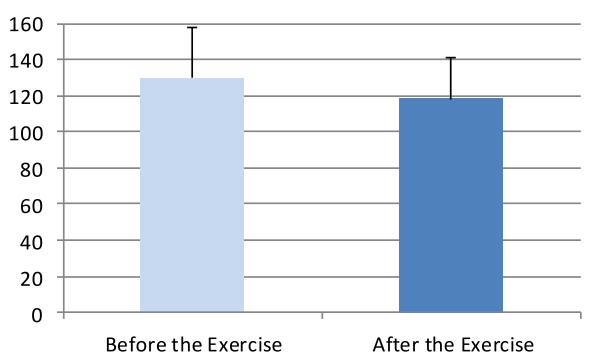

Fig. 4. (Continued) 


\section{Group B}
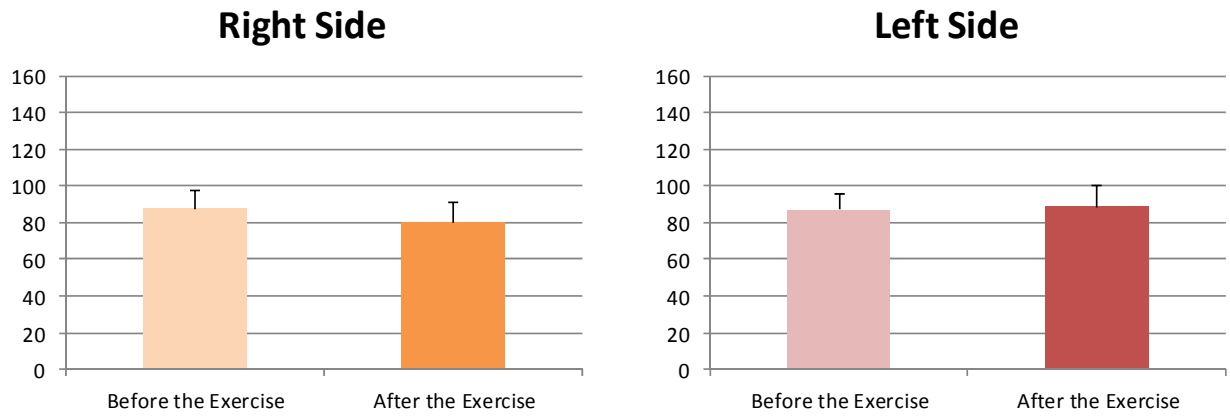

Unit: $\mathrm{cm}$

Group A: $100 \mathrm{~cm}$ or more in total tracks length before the exercise

Group B: less than $100 \mathrm{~cm}$ in total tracks length before the exercise

${ }^{*} \mathrm{p}<0.05$ : before the exercise vs. after the exercise

Fig. 4. Total tracks length while one-leg standing for 30 seconds before and after the exercise.

\section{To improve general reaction in human body}

\subsection{Whole body reaction time and muscle activity in jump action}

Whole body reaction time is used as a measurement of the body performance. Jump action is generally used for the measurement of the whole body reaction time. We have focused on trunk muscle activity in jump action. We then clarified the relationship between whole body reaction time and muscle activity in trunk muscles and leg extensor muscle in vertical jump action (Tanabe et al., 2010). Twelve healthy men (average 22.3 \pm 0.8 years old; range 21-24 years old) participated. When a red light, placed $2 \mathrm{~m}$ ahead, lit, a subject jumped vertically as quickly as possible. And the time from light stimulus to both feet aloft was measured and recorded 5 times each for the following muscles in the order given: right gastrocnemius muscle, right biceps femoris muscle, right internal oblique muscle, and right multifidus muscle by surface electromyograph. Fig.5 shows the results. Average whole body reaction time was $291.8 \pm 37.2 \mathrm{msec}$, while significance was found only in internal oblique muscle $(\mathrm{r}=0.80, \mathrm{p}<0.05)$ in the relationship between whole body reaction time and muscle contraction inception time (Fig.6). We suggest that a person capable of using his internal oblique muscle can start the foot-off action more quickly, and that the trunk muscles took part in whole body agility. 


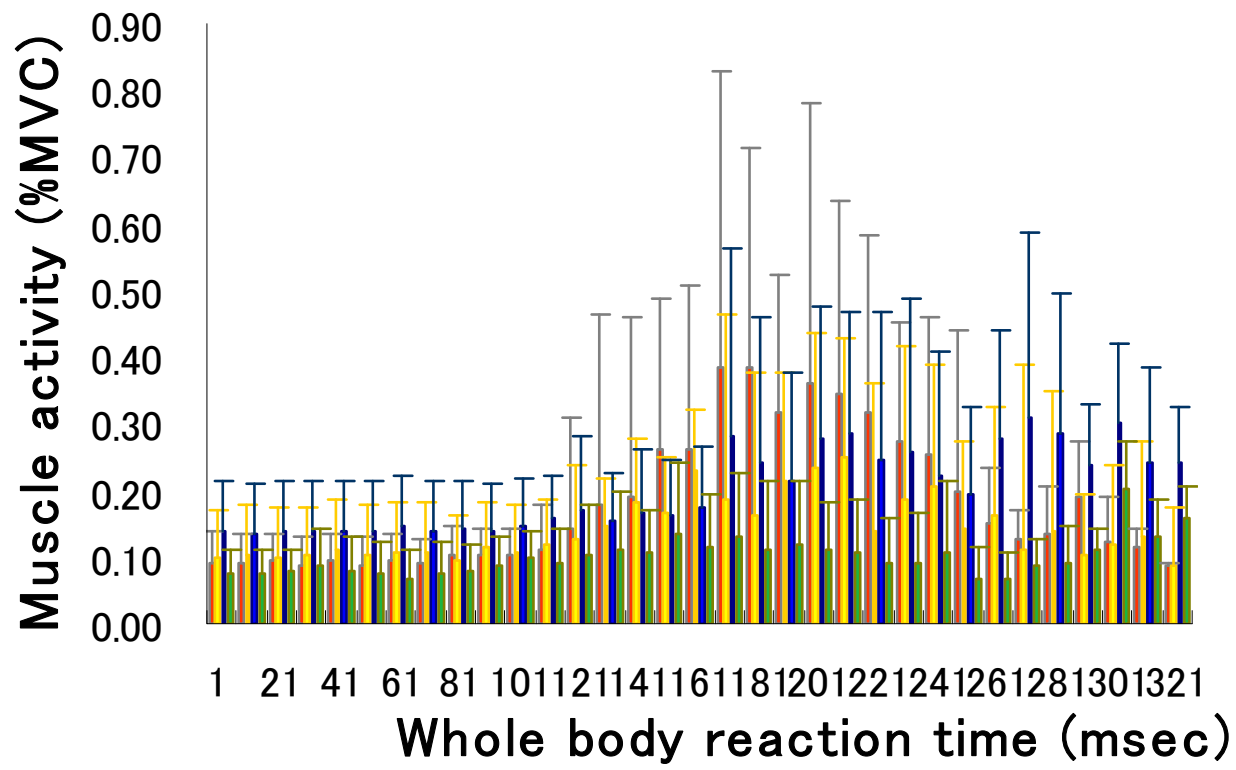

Red label: gastrocnemius muscle

Yellow label: biceps femoris muscle

Blue label: Internal oblique muscle

Green label: multifidus muscle

Fig. 5. EMG during jump action.

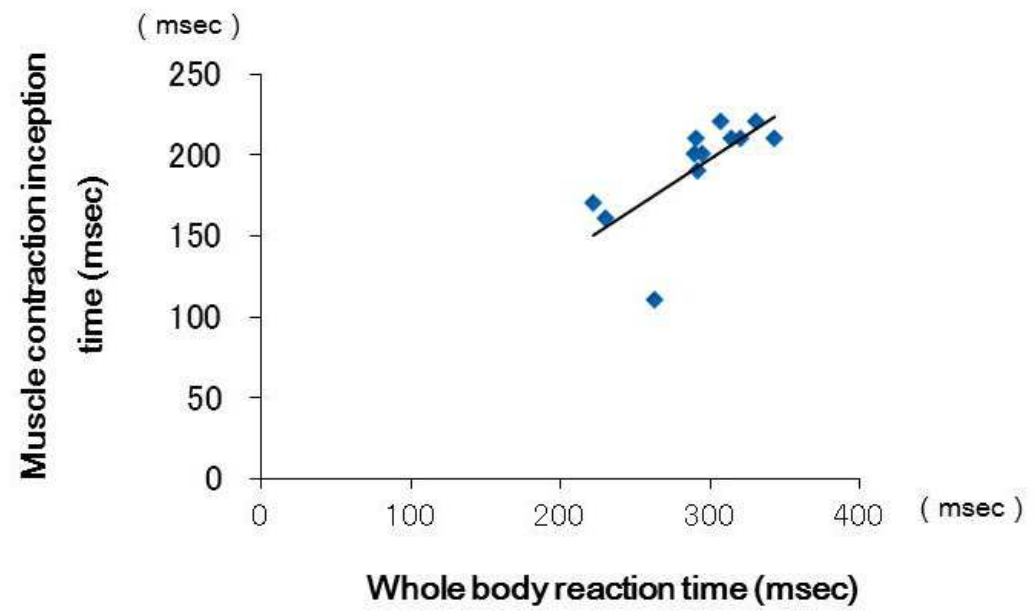

Fig. 6. Relationship between whole body reaction time and muscle contraction inception time. 


\subsection{Improving general reaction by expiration muscle training}

Having clarified the relationship between quick jump action and internal oblique muscle, we went on to determine how to train this particular muscle to shorten the whole body reaction time. Internal oblique muscle was activated by using expiration muscle training. Ten healthy men (average 21.6 \pm 0.7 years old; range $20-22$ years old) participated. The jump action given them was the same as in 4.1 above. Muscle activity was recorded from right internal oblique muscle. There was a significant shortening in whole body reaction time before and after the training (Fig.7). We have thus verified an effect of trunk muscle training, and internal oblique's role in the shortening of the whole body reaction time.

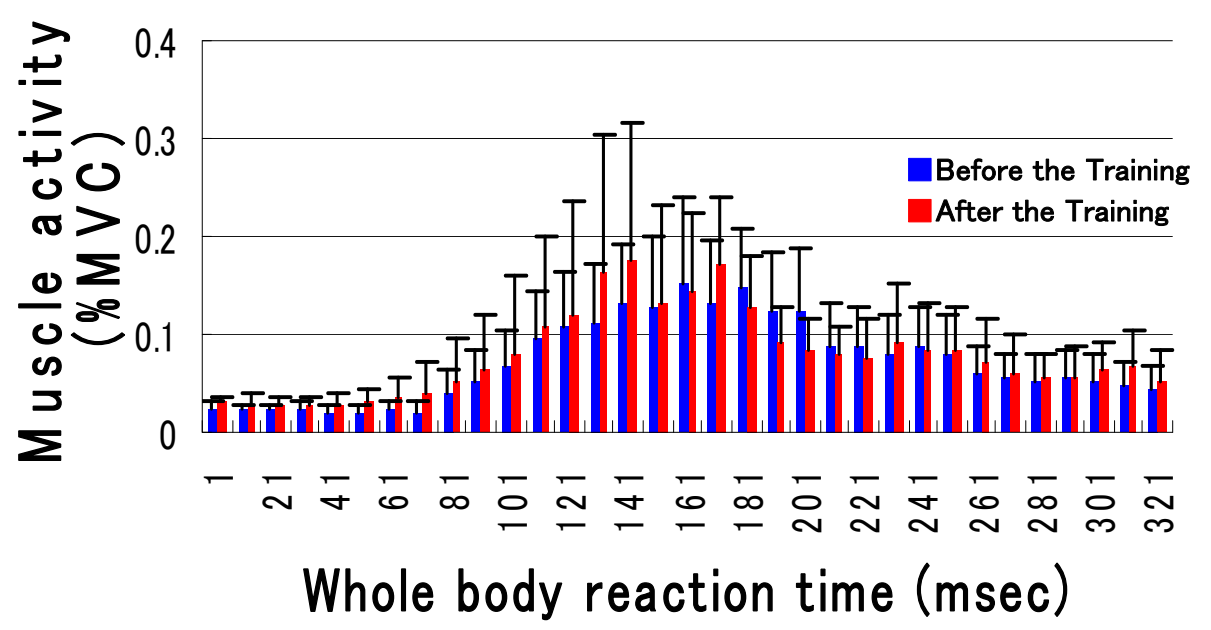

Fig. 7. Whole body reaction time before and after the training.

\section{Body performance and trunk muscle activity}

\subsection{Improving trunk muscle output after breath training}

We have demonstrated a positive effect of effort expiratory training on the shortening of whole body reaction time. Rectus abdominis, internal and external oblique, transversus abdominis, transversus thoracis, and internal intercostalis muscles are known as muscles that act in effort expiration. The four abdominal muscles work as a group in expiration to bend the chest, and to depress both the rib cage and the sternum. The intra-abdominal pressure is then indirectly raised, and the diaphragm is pushed forcefully up in the thoracic cavity via compression of the organs in the thorax. The action of transversus thoracis and internal intercostalis muscles in expiration is to depress the rib, which in turn decreases the amount of the thoracic cavity content. Rapid expiration, if needed, is done thanks to the action of these muscles. We then confirmed muscle activity in effort expiration before trying to determine whether stimulating the expiration muscles would improve the trunk muscles' muscular power. Six healthy men (average 22.3 \pm 0.5 years old; range 21-23 years old) participated. The muscular power of the trunk muscles was compared before and after an effort expiration action using a spirometer. Surface electromyogram was used to trace the 
muscle activity under measurement. Internal oblique, rectus abdominis, multifidus, and erector spinae muscles were chosen for recording. The muscular power of the flexor and extensor muscles of the trunk was measured twice each by isokinetic movement of $60^{\circ} / \mathrm{sec}$. There was a significant increase $(\mathrm{p}<0.05)$ in average power value of the extensor muscle. All the subjects showed an increase in the activity of internal oblique muscle while using a spirometer. These results suggest that the approach to the inner, or core, muscles comes to influence the stability of the trunk, facilitating the work of the outer muscles.

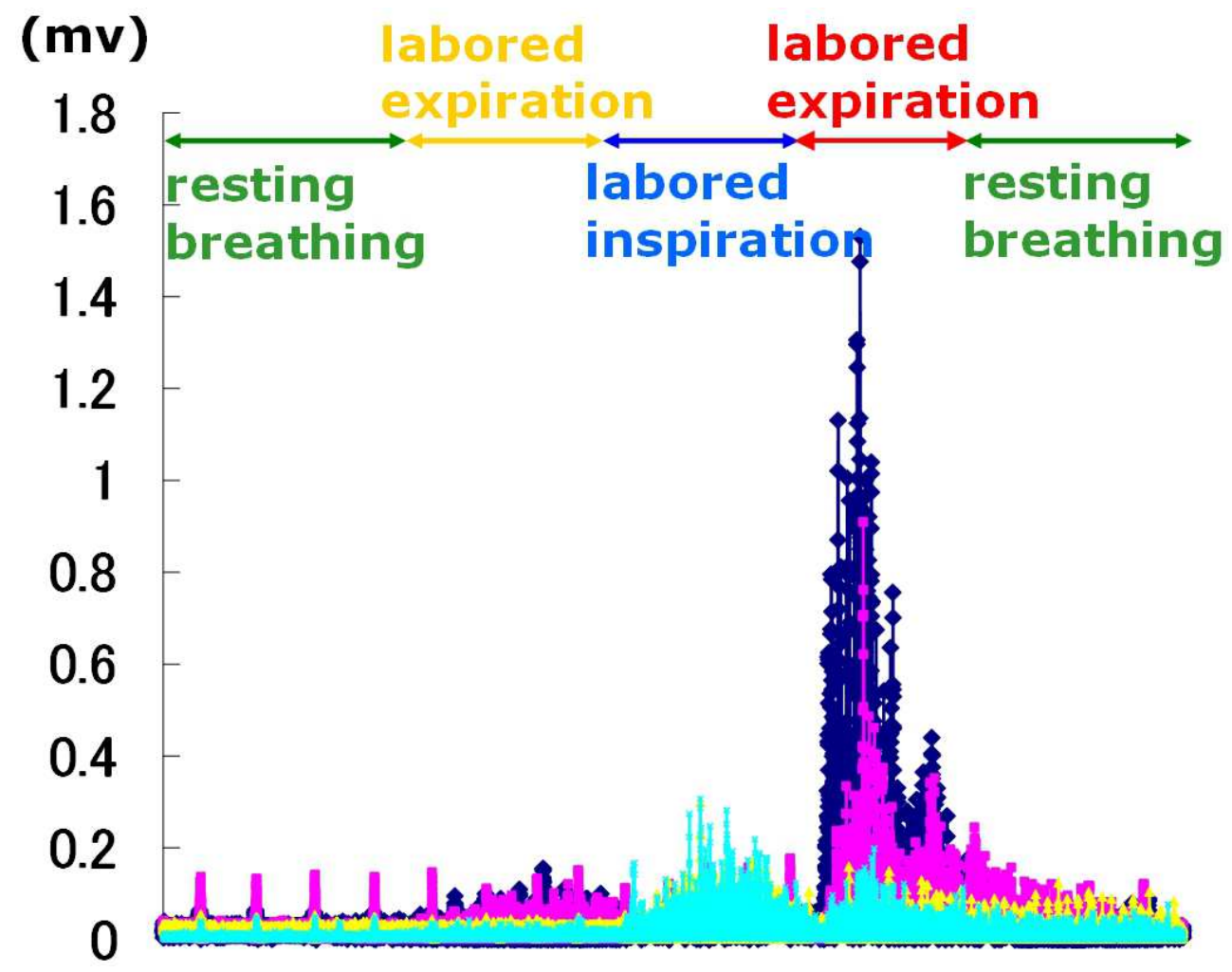

Fig. 8. EMG during labored respiration.

EMG black line: Internal oblique muscle, pink line: Rectus abdominis muscle, yellow line: Multifidus muscle, light blue line: Erector spinae muscle 


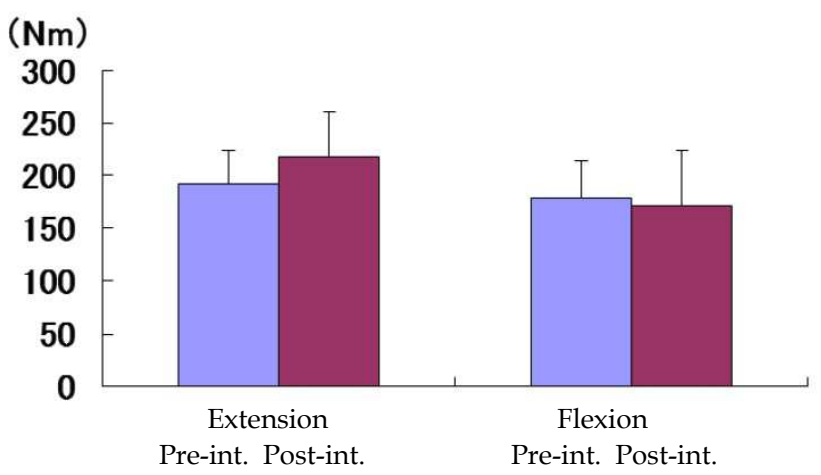

Fig. 9. Maximum torque value of the pre- and post-intervention.

\subsection{Relationship between posture and trunk muscle activity - research by means of electromyography and ultrasound imagery}

We have a number of research projects focusing on the relationship between body trunk muscles and body performance. There now exists a variety of trunk muscle training methods, including machine-assisted exercise regimens in the gym. In general, however, trunk muscles are not used all that much in an average person's daily life, so that even a simple home exercise routine can prove effective in the strengthening of trunk muscles. That being the case, we tried to determine, using surface electromyography and ultrasound imagery, whether keeping a posture for a certain length of time would enhance activation of the trunk muscles. Ten healthy adult men (average $21.5 \pm 0.5$ years old; range 21-22 years old) participated in this program. The measurement postures were i) resting supine position (rest), ii) on knee-elbow position (knee-elbow), iii) elbow setting up lateral decubitus position (side-lying bridge), and iv) two legs bent and raised supine position (supine). An electrode was attached to external oblique muscle between ribs and to internal oblique muscle on the bottom of the abdomen. Ultrasound imagery was taken from a part of the abdominal side so that we could confirm all three layers (external oblique, internal oblique, and transversus abdominis muscles). Results showed that internal oblique muscle worked more actively in the side-lying bridge than in the rest of the positions by ultrasound imagery research. This fact should in passing be incorporated into an effective trunk muscle training program.

EMG results showed that external oblique (EO) muscle activity in side-lying bridge was higher than in other positions, but internal oblique/external oblique ratio (IO/EO ratio) of muscle activity was lower than in other positions (Fig. 10). The outcome prompted us to assume that this posture (side-lying bridge) enhanced the muscular activity of outer muscle more markedly than that of inner muscle. In supine position, in contrast, internal oblique (IO) and IO/EO ratio of muscle activity were higher than in other positions, which means that inner muscle is promoted more in muscle activity than in outer muscle (also Fig. 10).

Changes of muscle thickness taken by ultrasound imagery showed an increase in the transverse diameter of a muscle, which was indicative of sustained muscular contraction (Fig. 11). Because of a 1.5-fold increase in IO/EO ratio in both knee-elbow and side-lying bridge positions in outer muscle thickness, we suggest that inner muscle is definitely easier to grow in muscle thickness in both these positions (Fig. 12). 
EMG showed higher IO and IO/EO ratio in supine position than in other positions, but that was not the case in ultrasound imagery study. The relationship between the two awaits clarification in the future.

\section{EO}

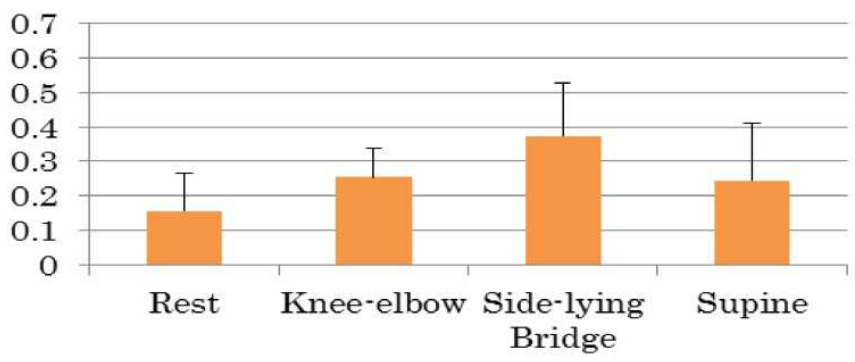

IO

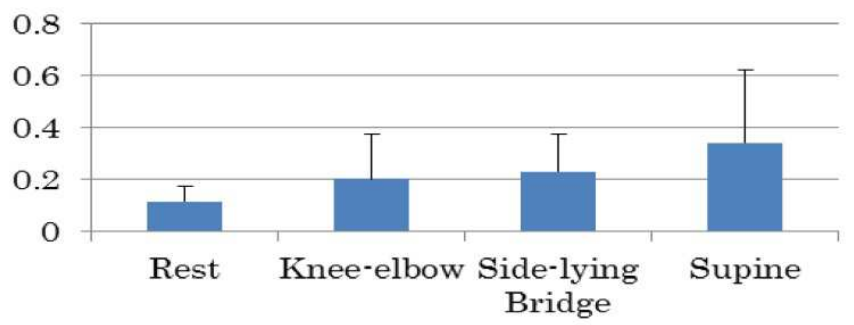

\section{IO/EO ratio}

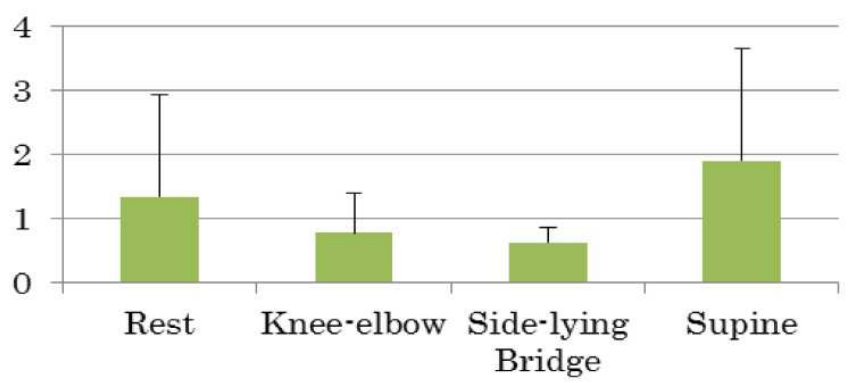

Abbreviations, EO, external oblique muscle; IO, internal oblique muscle; IO/EO ratio, internal oblique muscle/external oblique muscle ratio;

Fig. 10. EMG of EO, IO, and IO/EO ratio in each position. 


\section{EO}

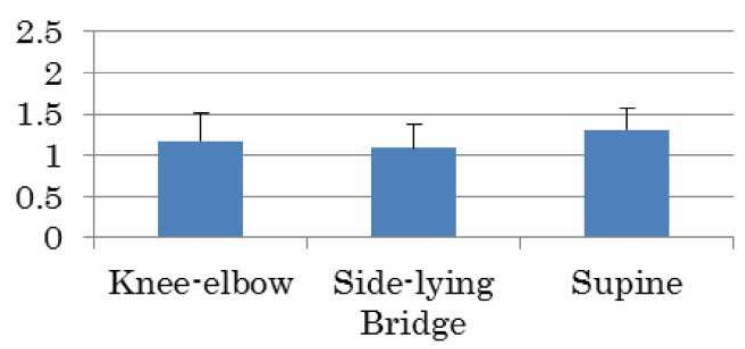

IO

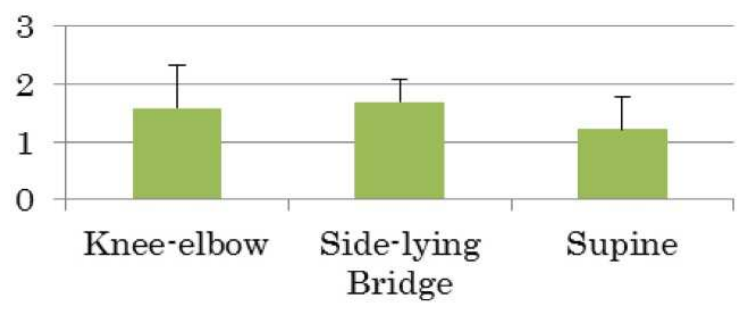

$\operatorname{Tr} \mathrm{A}$

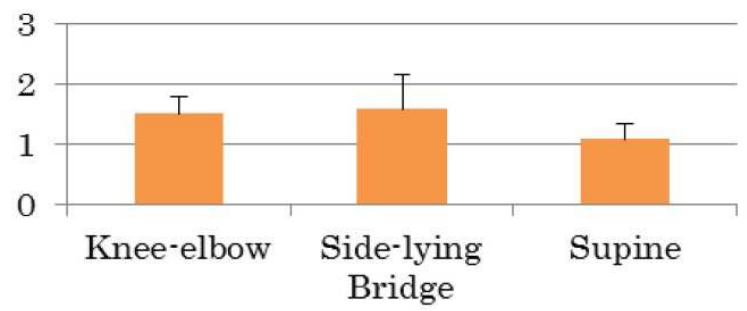

Abbreviations, EO, external oblique muscle; IO, internal oblique muscle; $\operatorname{Tr} \mathrm{A}$, transversus abdominis muscle;

Fig. 11. Muscle contracted-rest thickness of EO, IO, and TrA in each position. 


\section{IO/EO ratio}

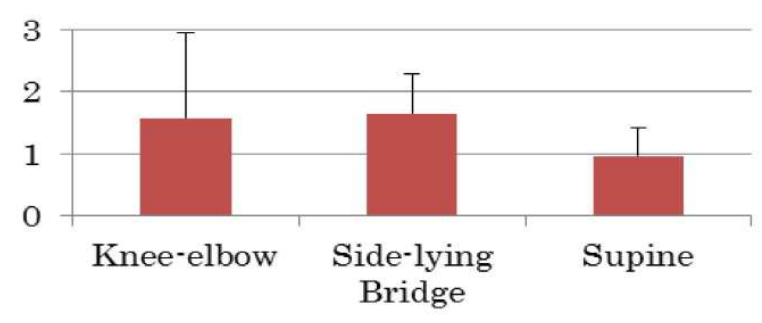

\section{$\operatorname{Tr} \mathrm{A} / \mathrm{EO}$ ratio}

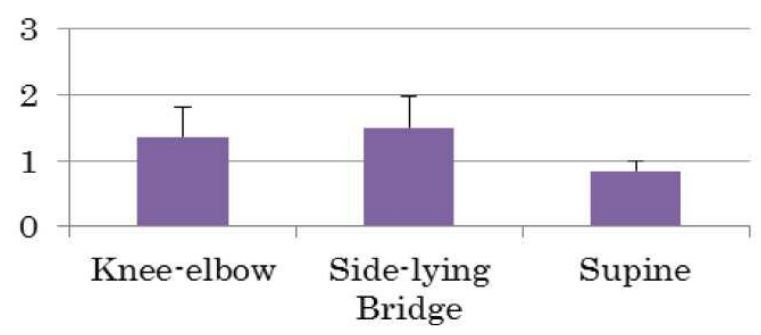

\section{$\operatorname{Tr} \mathrm{A} / \mathrm{IO}$ ratio}

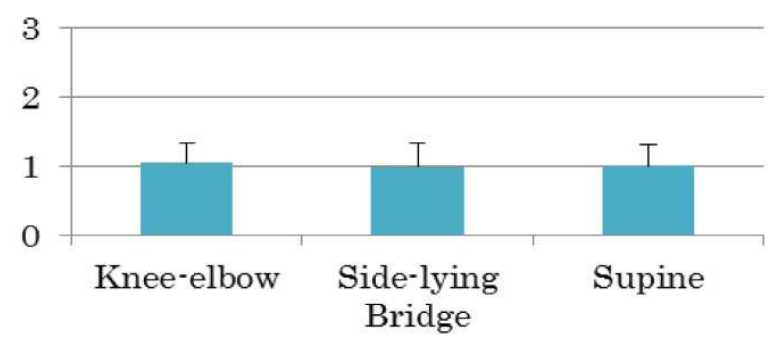

Abbreviations, $\mathrm{IO} / \mathrm{EO}$ ratio, internal oblique muscle/external oblique muscle ratio; $\mathrm{TrA} / \mathrm{EO}$ ratio, transversus abdominis muscle/external oblique muscle ratio; $\mathrm{TrA} / \mathrm{IO}$ ratio, transversus abdominis muscle/internal oblique muscle ratio;

Fig. 12. Muscle contracted-rest thickness of IO/EO, TrA/EO, and TrA/IO ratios in each position. 


\section{Conclusion}

A patient is referred to us physical therapists for an evaluation and treatment of his/her condition, we come up with a list of signs and symptoms, and we try to determine how best to proceed. We know that by increasing the patient's strength and endurance we will often see a decrease (or disappearance) in some of those signs and symptoms, ostensibly curing the patient. We hope to have shown that electromyography is a means that is highly useful, therefore important, in the evaluation of the conditions of a patient's trunk muscle activity.

\section{Acknowledgements}

This study was supported in part by The Japan Health Foundation for the Prevention of Chronic Diseases and the Improvement of QOL of Patients.

\section{References}

Kai, S.; Yoshimoto, R.; Nakahara, M.; Murakami, S.; Watari, K.; Takahashi, S. (2008a). Change of the muscular activity by activation training of the lower trunk muscle in two-leg to one-leg standing shift of an elderly man, J. Phys. Ther. Sci., vol. 20, pp. 6366

Kai, S.; Yoshimoto, R.; Nakahara, M.; Murakami, S.; Watari, K.; Takahashi, S. (2008b). Trunk muscle activity in two-leg standing to one-leg standing in healthy elderly adults, $J$. Phys. Ther. Sci., vol. 20, pp. 77-80

Lee, D. (2004). The pelvic girdle, $3^{\text {rd }}$ ed, Elsevier

Richardson, C.; Hodges, P.; Hides, J. (2004). Therapeutic exercise for lumbopelvic stabilization, $2^{\text {nd }}$ ed, Elsevier

Tanabe, T.; Yamamoto, H.; Ariyoshi, Y.; Matsumoto, A.; Momii, Y.; Koga, M.; Yoshino, C.; Kai, S.; Takahashi, S. (2010). Whole body reaction time and muscle activity in jump action, The $45^{\text {th }}$ Congress of JPTA., vol. 37, pp. 1521 


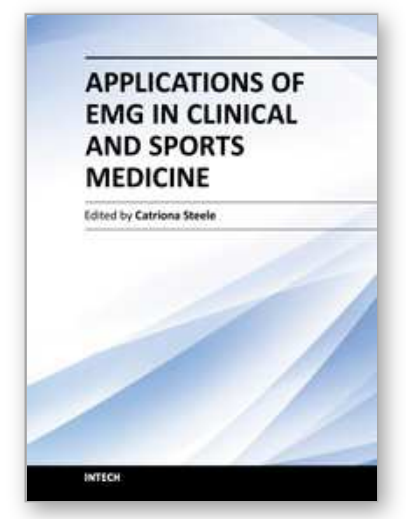

\author{
Applications of EMG in Clinical and Sports Medicine \\ Edited by Dr. Catriona Steele
}

ISBN 978-953-307-798-7

Hard cover, 396 pages

Publisher InTech

Published online 11, January, 2012

Published in print edition January, 2012

This second of two volumes on EMG (Electromyography) covers a wide range of clinical applications, as a complement to the methods discussed in volume 1. Topics range from gait and vibration analysis, through posture and falls prevention, to biofeedback in the treatment of neurologic swallowing impairment. The volume includes sections on back care, sports and performance medicine, gynecology/urology and orofacial function. Authors describe the procedures for their experimental studies with detailed and clear illustrations and references to the literature. The limitations of SEMG measures and methods for careful analysis are discussed. This broad compilation of articles discussing the use of EMG in both clinical and research applications demonstrates the utility of the method as a tool in a wide variety of disciplines and clinical fields.

\title{
How to reference
}

In order to correctly reference this scholarly work, feel free to copy and paste the following:

Satoru Kai (2012). Trunk Muscle Activity Affects the Level of Performance in Human Body, Applications of EMG in Clinical and Sports Medicine, Dr. Catriona Steele (Ed.), ISBN: 978-953-307-798-7, InTech, Available from: http://www.intechopen.com/books/applications-of-emg-in-clinical-and-sports-medicine/trunk-muscleactivity-affects-the-level-of-performance-in-human-body

\section{INTECH}

open science | open minds

\author{
InTech Europe \\ University Campus STeP Ri \\ Slavka Krautzeka 83/A \\ 51000 Rijeka, Croatia \\ Phone: +385 (51) 770447 \\ Fax: +385 (51) 686166 \\ www.intechopen.com
}

\author{
InTech China \\ Unit 405, Office Block, Hotel Equatorial Shanghai \\ No.65, Yan An Road (West), Shanghai, 200040, China \\ 中国上海市延安西路65号上海国际贵都大饭店办公楼405单元 \\ Phone: +86-21-62489820 \\ Fax: +86-21-62489821
}


(C) 2012 The Author(s). Licensee IntechOpen. This is an open access article distributed under the terms of the Creative Commons Attribution 3.0 License, which permits unrestricted use, distribution, and reproduction in any medium, provided the original work is properly cited. 